\title{
Association of Low Maternal Plasma Glucose after Oral Glucose Challenge Test with Small for Gestational Age Neonate
}

\author{
Rajeshwari G Bhat, KV Bhagya, Pratap Kumar
}

\section{ABSTRACT}

Aims and objectives: To study the association of low maternal plasma sugar with birth weight and neonatal morbidity.

Materials and methods: Glucose challenge test was performed in low risk women, the birth weight and neonatal morbidities were compared between women with low GCT $(<88 \mathrm{mg} / \mathrm{dl})$ and normal GCT (88-139 mg/dl).

Results: Incidence of small for gestational age (<2500 gm) was significantly more in women with low GCT $(17.3 \%$ vs $7.3 \%)$, but difference in NICU admission between the two groups was not significant statistically.

Conclusion: Prevalence of small for gestational age neonate was significantly higher in women with low GCT compared to women with normal GCT.

Keywords: Glucose challenge test, Small for gestational age.

How to cite this article: Bhat RG, Bhagya KV, Kumar $P$. Association of Low Maternal Plasma Glucose after Oral Glucose Challenge Test with Small for Gestational Age Neonate. Int J Infertility Fetal Med 2012;3(1):22-25.

Source of support: Nil

Conflict of interest: None declared

\section{INTRODUCTION}

Glucose is a simple energy substrate and important in fetal growth and development. The association between maternal hyperglycemia in pregnancies with gestational diabetes and fetal macrosomia, operative deliveries, shoulder dystocia, and poor fetal outcome is well known. Small for gestational age (SGA) fetuses make up 3 to $10 \%$ of pregnancies. Maternal hypoglycemia has been reported to be linked with both intrauterine growth restriction and poor neonatal outcome. Abell and Beischer ${ }^{1}$ found the mean 3-hour blood glucose level following an oral glucose tolerance test (GTT) to be significantly lower in low birth weight intrauterine growth restricted (LBW IUGR) fetuses. Glucose challenge test with $50 \mathrm{~g}$ is performed routinely in pregnancy and hypoglycemia following this screening test, if it correlates with neonatal outcome, would be valuable in identifying pregnancies at risk for an adverse event.

Date of Received: 15-02-12

Date of Acceptance: 16-02-12

Date of Publication: January 2012
The aim of the study was to determine if pregnancies with low plasma sugar following a 50 gm oral glucose challenge test were at increased risk of having SGA neonate and adverse neonatal outcome.

\section{MATERIALS AND METHODS}

This study was an observational cohort study done from August 2008 to September 2010 at a tertiary referral centre. Antenatal women without risk factors for diabetes were screened for gestational diabetes with a 50 g glucose challenge test between 24 and 28 weeks of gestation. Venous blood was collected one hour after ingestion of glucose irrespective of the last meal. Tests were performed using glucose oxidase-peroxidase based method. All low risk singleton pregnancies with excellent dating with glucose challenge taste (GCT) $\leq 139 \mathrm{mg} / \mathrm{dl}$, who delivered at term, were included in the study. Women with preexisting medical conditions, such as hypertension, cardiac disease, bronchial asthma and thyroid disorder and those with fetal anomalies were excluded from the study. There were 450 women who were divided into two groups based on the GCT values. Low GCT in our study was defined as $\leq 88 \mathrm{mg} / \mathrm{dl}$ ( $\leq 5$ th percentile). There were 150 women with GCT $\leq 88 \mathrm{mg} / \mathrm{dl}$ (subjects/cases). These 150 cases were matched with 300 randomly selected controls who had GCT values between 89 to $139 \mathrm{mg} / \mathrm{dl}$ with similar inclusion and exclusion criteria.

Outcome measures studied were birth weight, NICU admission and mortality. SGA is defined birth weight less than the 10 th percentile. In our study, $2.5 \mathrm{~kg}$ was the 10 th percentile. Hence, birth weight of $\leq 2.49 \mathrm{~kg}$ was taken as SGA and birth weight $\geq 2.5 \mathrm{~kg}$ was taken as normal. The data were analyzed using the statistical package for the social sciences 11.5. The comparison of outcomes among the two groups was done by Chi-square test, Student's t-test, Mann-Whitney test and post-hoc test, wherever applicable. A p-value of $<0.05$ was considered statistically significant.

\section{RESULTS}

Table 1 shows comparison of known independent risk factors for SGA, such as age, parity, socioeconomic status, body mass index, interval between pregnancies, 
mean weight gain, presence of anemia (hemoglobin percent) and gestational age at delivery between subject and control groups. The differences were not statistically significant, therefore, were matched.

The overall incidence of SGA in our study was $10.7 \%$ (48/450). The incidence of SGA in the low GCT group was $17.3 \%(26 / 150)$ and, in the normal GCT group was $7.3 \%$ (22/300). p-value was significant. The odds ratio was 2.65 , indicating that women with low GCT are 2.65 times at higher risk of having SGA babies than women with normal GCT (Table 2).

The mean birth weight in women with GCT $<70 \mathrm{mg} / \mathrm{dl}$, 71 to $80 \mathrm{mg} / \mathrm{dl}$ and 81 to $88 \mathrm{mg} / \mathrm{dl}$ was $2.60 \pm 0.843 \mathrm{~kg}$, $2.67 \pm 0.756 \mathrm{~kg}$ and $2.80 \pm 0.598 \mathrm{~kg}$ respectively. Though the p-value was not significant as the GCT values increased a rising trend in the birth weight was observed.

Neonates who got admitted in intensive care unit in the low GCT group were $24.7 \%$ (37/150), and in the normal GCT group were $17.7 \%(53 / 300)$. The NICU admissions were more in low GCT group but the p-value was not significant. The NICU admissions among the SGA neonates of both the groups were $35.4 \%$ (17/48) and among the appropriate for gestational age (AGA) neonates were $18.2 \%$ (73/402). The p-value $(0.007)$ was significant.

Table 3 shows that $34.6 \%(9 / 26)$ of SGA neonates of low GCT group and $36.4 \%(8 / 22)$ of SGA neonates of normal GCT group required NICU admission. Small for gestational age neonates of both groups were at higher risk for NICU admission.

Reasons for NICU admissions in both the groups include hypoglycemia, respiratory distress syndrome, sepsis, seizures and hyperbilirubinemia. Among various neonatal morbidities, neonatal hypoglycemia and related consequences, like seizures, are expected to be more in low GCT group, but the differences were either statistically not significant or too small a number to come to a conclusion.

There was one neonatal death in each group. The baby in the study group had diffuse muscular dystrophy and, in the control group, the cause of death was pneumonia and metabolic acidosis.

\begin{tabular}{|c|c|c|c|}
\hline Risk factors & $\begin{array}{l}\text { Low GCT } \\
(n=150)\end{array}$ & $\begin{array}{l}\text { Normal GCT } \\
\quad(n=300)\end{array}$ & $p$-value \\
\hline Mean age (year) & $26 \pm 3.41$ & $27 \pm 3.62$ & 0.427 \\
\hline \multicolumn{4}{|l|}{ Parity } \\
\hline - Primigravida & $92(61.3 \%)$ & 179 (59.7\%) & 0.897 \\
\hline - Multigravida & $58(38.7 \%)$ & $121(40.3 \%)$ & \\
\hline \multicolumn{4}{|l|}{ Socioeconomic status } \\
\hline - Upper & $29(38.7 \%)$ & $77(25.7 \%)$ & 0.252 \\
\hline - Upper middle & $120(80 \%)$ & $219(73 \%)$ & \\
\hline - Lower middle & $1(0.7 \%)$ & $4(1.3 \%)$ & \\
\hline \multicolumn{4}{|l|}{ BMI } \\
\hline - $<20$ & $52(34.7 \%)$ & $97(32.3 \%)$ & 0.732 \\
\hline - $21-22$ & $46(30.6 \%)$ & $103(34.3 \%)$ & \\
\hline$\cdot>23$ & $52(34.7 \%)$ & $100(33.4 \%)$ & \\
\hline Interval between pregnancies in years & $4(2.8,5)$ & $3(2.4)$ & $0.010^{*}$ \\
\hline Weight gain in kg & $9.1( \pm 2.5)$ & $9.2( \pm 2.9)$ & 0.866 \\
\hline Anemia & $36(24 \%)$ & $61(20.3 \%)$ & 0.396 \\
\hline Gestational age at delivery in weeks & $38.6( \pm 1.2)$ & $38.6( \pm 0.9)$ & 0.149 \\
\hline
\end{tabular}

*Interval between pregnancies is more in low GCT group

\begin{tabular}{ccccc} 
& \multicolumn{4}{c}{ Table 2: Comparison of birth weight } \\
\hline Birth weight & Low GCT $(n=150)$ & Normal GCT $(n=300)$ & & Odds ratio 2.65 \\
\hline SGA & $26(17.3 \%)$ & $22(7.3 \%)$ & p-value 0.002 (significant) & O \\
\hline AGA & $124(82.7 \%)$ & $278(92.7 \%)$ &
\end{tabular}

\begin{tabular}{|c|c|c|c|c|}
\hline \multicolumn{5}{|c|}{ Table 3: Comparison of NICU admissions } \\
\hline GCT groups & \multicolumn{2}{|c|}{$\begin{array}{l}\text { Low GCT } \\
(n=150)\end{array}$} & \multicolumn{2}{|c|}{$\begin{array}{l}\text { Normal GCT } \\
\quad(n=300)\end{array}$} \\
\hline NICU admissions & \multicolumn{2}{|c|}{$37(24.7 \%)$} & \multicolumn{2}{|c|}{$53(17.7 \%)$} \\
\hline Birth weight groups & $\begin{array}{c}\text { SGA }(n=26) \\
n(\%)\end{array}$ & $\begin{array}{c}\text { AGA }(n=124) \\
n(\%)\end{array}$ & $\begin{array}{c}\text { SGA }(n=22) \\
n(\%)\end{array}$ & $\begin{array}{c}\text { AGA }(\mathrm{n}=278) \\
\mathrm{n}(\%)\end{array}$ \\
\hline
\end{tabular}




\section{DISCUSSION}

The placental transfer of glucose is dependent upon maternal plasma glucose, uterine and placental blood flow. Cause for maternal hypoglycemia is not known. In women whose caloric intake is chronically low, basal glucose levels are lower than in women with adequate caloric intake, this extremely low glucose levels seem to be inadequate to maintain the gradient across the placenta. Hence, such mothers have a high chance of giving birth to low birth weight neonates. Insulin is believed to be the fetal growth hormone and it is partly regulated by fetal glucose levels that are in turn determined by the glucose gradient between the maternal and fetal compartments. Thus maternal hypoglycemia would lead to fetal hypoglycemia and fetal hypoinsulinemia and possibly fetal growth restriction. Thus, more severe the hypoglycemia, greater is likelihood of SGA neonates.

Several studies have been undertaken to correlate low maternal plasma glucose after a GCT or GTT with low birth weight and adverse pregnancy outcomes. Many have shown an increase in delivery of a small for gestational age neonate and increase in adverse perinatal outcomes, such as neonatal hypoglycemia, fetal death, etc.

In a study done by Abell and Beischer, ${ }^{2}$ the incidence of SGA was $12.8 \%$ when one hypoglycemic value was present and an incidence of $18.4 \%$ when more than one hypoglycemic value was present in patients who underwent GTT in the third trimester of pregnancy.

Study done by Victor A Kouzami ${ }^{3}$ showed an incidence of $15 \%$ of LBW IUGR in the presence of hypoglycemia. The same association was noted in a study done by JL Bienstock $^{4}$ in which 27/207 (13\%) neonates whose mothers had low GCT were SGA compared with 23/369 (6.2\%) with a normal GCT which was statistically significant.

Leela Raman ${ }^{5}$ et al studied the effect of maternal levels of fasting blood glucose on fetal outcome. They noted that $40 \%$ of the mothers with low glucose levels gave birth to SGA neonates. In a study done by Gustavo Lugo, ${ }^{6}$ hypoglycemia was noted as the cause of intrauterine growth retardation in 26/211 (12\%) patients. Our study also showed statistically significant incidence of SGA in the low GCT group [17.3\% (26/150)] compared to normal GCT group $[7.3 \%(22 / 300)]$. The odds ratio was 2.65 , indicating that women with low GCT are 2.65 times at higher risk of having SGA babies than women with normal GCT.

Studies show mixed results regarding NICU admission with relation to low maternal plasma sugars. Some studies have shown that maternal hypoglycemia was associated with adverse neonatal outcome, such as hypoglycemia, sepsis, respiratory distress, seizures, hyperbilirubinemia and perinatal mortality. Jeffrey $\mathrm{H}$ Feinberg ${ }^{7}$ et al found that more special/neonatal admissions occurred in the hypoglycemic group 48/334 (14.4\%) compared to 29/334 (8.7\%) euglycemic group which was statistically significant.

In our study, NICU admission seen in the low GCT group was $24.7 \%$ (37/150) when compared to $17.7 \%$ $(53 / 300)$ women with normal GCT which was not statistically significant. This was comparable with the study done by Calfee who observed that hypoglycemia after 1 hour glucose challenge test was not predictive of adverse perinatal outcome. Similar results were also observed by Piper JM et $\mathrm{al}^{8}$ that there was no difference in the NICU admissions between hypoglycemic mothers and controls.

In our study, $35.4 \%(17 / 48)$ of SGA neonates had morbidity compared to $18.2 \%$ (73/402) of AGA neonates which was statistically significant. This was comparable to the study done by Norman H Daikoku ${ }^{9}$ who observed NICU admission of $40 \%$ in SGA neonates.

Patient with low GCT value may have either a lower baseline blood sugar level, a hyperactive insulin response or their dietary intake from either food type or meal spacing may foster lower blood sugar levels. Neonatal hypoglycemia can cause irritability, apnea and tachypnea which could be interpreted as either respiratory distress or sepsis. This may be one of the possible causes of increased NICU admission. In our study, hypoglycemia was seen only in $1.3 \%(2 / 150)$ of neonates of low GCT.

In the study done by Leela Raman, nine still births occurred to mothers with blood glucose levels $\leq 44 \mathrm{mg} / \mathrm{dl}$ and three still births to mothers with normal blood glucose levels. Neonatal deaths in our study were incidental, not related to maternal glucose levels.

As we have matched both subjects and controls with regards to socioeconomic status, BMI, interval between pregnancies, hemoglobin and subsequent weight gain, it is less likely that dietary intake is the cause for hypoglycemia. Therefore, further research is required why few women have exaggerated hypoglycemia after challenging with glucose.

A possible limitation of our study is that only one GCT value done between 24 to 28 weeks was included. Reproducibility of the test by repeating it after 3 to 7 days or consistency of hypoglycemia by repeating the test at 32 to 34 weeks when maximum fetal growth occurs was not assessed. Similar study can be performed by using fasting/postprandial blood sugars rather than challenging with glucose to know, if the growth lag is due to maternal hypoglycemia per se.

\section{CONCLUSION}

Prevalence of SGA neonate was significantly higher in women with low GCT compared to women with normal 
GCT. Women who had low GCT were at 2.6 times higher risk of delivering small for gestational age neonates when compared to women with normal GCT. Increased NICU admission may be attributable to small for gestational age neonate rather than maternal hypoglycemia.

\section{REFERENCES}

1. Abell DA, Beischer NA. The effects of hypoglycemia and hyperglycemia on pregnancy outcome. Aust NZJ Obstet Gynecol 1976;16:75.

2. Abell DA. The significance of abnormal glucose tolerance (hyperglycemia and hypoglycaemia) in pregnancy. Br. J Obstet Gynecol 1979;86:214.

3. Kousami Victor A, Ginsburg David S, Daikoku Norman H, Johnson John WC. The glucose tolerance test as a means of identifying intrauterine growth retardation. Am J Obstet Gynecol 1981;139:423.

4. Beinstock JL, Holcroft CJ, Althaus J. Small fetal abdominal circumference in the second trimester and subsequent low maternal plasma glucose after a glucose challenge test is associated with the delivery of a small for gestational age neonate. Ultrasound Obstet Gynecol 2008;31:517-19.

5. Raman Leela, Rao Veena A, Kumar S. Influence of maternal levels of blood glucose on fetal outcome. Int J Gynecol Obstet 1982;20:363-69.

6. Lugo Gustavo, Cassady George. Intrauterine growth retardation. Clinicopathologic findings in 233 consecutive infants. Am J Obstet Gynecol 1971;109:616-22.
7. Feinberg Jeffery H, Magann Everett F, Morrison John C, Polizzotto Michael J. Does maternal hypoglycemia during screening glucose assessment identify a pregnancy at risk for adverse perinatal outcome. Journal of Perinatalogy 2005;25: 509-13.

8. Piper JM, Field NT, Higby K, Elliott BD, Langer O. Maternalfetal metabolism and growth retardation. J Reprod Med 1996;41:761-66.

9. Daikoku Norman H, Johnson John WC, Claudia Graf, Kevin Kearney CNM, Tyson John E, King Theodore M. Patterns of intrauterine growth retardation. Obstetrics and Gynecology 1979;54(2):211-19.

\section{ABOUT THE AUTHORS}

\section{Rajeshwari G Bhat (Corresponding Author)}

Associate Professor, Department of Obstetrics and Gynecology Kasturba Medical College and Hospital, Manipal, Karnataka India, Fax: 0820, Phone: 0820-2571201, Extn-22176 e-mail: rajigbhat@yahoo.co.in

\section{KV Bhagya}

Senior Resident, Department of Obstetrics and Gynecology, Kasturba Medical College and Hospital, Manipal, Karnataka, India

\section{Pratap Kumar}

Professor, Department of Obstetrics and Gynecology, Kasturba Medical College and Hospital, Manipal, Karnataka, India 